\title{
Modelling age and secular differences in fitness between basketball players
}

\author{
ERIC J. DRINKWATER ${ }^{1,3}$, WILL G. HOPKINS ${ }^{2}$, MICHAEL J. MCKENNA ${ }^{3}$, \\ PATRICK H. HUNT ${ }^{4}$, \& DAVID B. PYNE \\ ${ }^{1}$ School of Human Movement Studies, Charles Sturt University, Bathurst, NSW, Australia, ${ }^{2}$ Division of Sport and \\ Recreation, Auckland University of Technology, Auckland, New Zealand, ${ }^{3}$ School of Human Movement, Recreation and \\ Performance, Centre for Ageing, Rehabilitation, Exercise and Sport, Victoria University, Melbourne, VIC, Australia, \\ ${ }^{4}$ Basketball Australia, Sydney, NSW, Australia and ${ }^{5}$ Department of Physiology, Australian Institute of Sport, Canberra, \\ ACT, Australia
}

(Accepted 4 fuly 2006)

\begin{abstract}
Concerns about the value of physical testing and apparently declining test performance in junior basketball players prompted this retrospective study of trends in anthropometric and fitness test scores related to recruitment age and recruitment year. The participants were 1011 females and 1087 males entering Basketball Australia's State and National programmes (1862 and 236 players, respectively). Players were tested on $2.6 \pm 2.0$ (mean $\pm s$ ) occasions over $0.8 \pm 1.0$ year. Test scores were adjusted to recruitment age (14-19 years) and recruitment year (1996-2003) using mixed modelling. Effects were estimated by log transformation and expressed as standardized (Cohen) differences in means. National players scored more favourably than State players on all tests, with the differences being generally small (standardized differences, $0.2-0.6)$ or moderate $(0.6-1.2)$. On all tests, males scored more favourably than females, with large standardized differences $(>1.2)$. Athletes entering at age 16 performed at least moderately better than athletes entering at age 14 on most tests (standardized differences, 0.7-2.1), but test scores often plateaued or began to deteriorate at around 17 years. Some fitness scores deteriorated over the 8-year period, most notably a moderate increase in sprint time and moderate (National male) to large (National female) declines in shuttle run performance. Variation in test scores between National players was generally less than that between State players (ratio of standard deviations, $0.83-1.18$ ). More favourable means and lower variability in athletes of a higher standard highlight the potential utility of these tests in junior basketball programmes, although secular declines should be a major concern of Australian basketball coaches.
\end{abstract}

Keywords: Anthropometry, athlete, adolescent, fitness

\section{Introduction}

Several anthropometric and fitness tests, common to basketball programmes throughout Australia (Stapff, 2000), are often used by coaches to recruit new players into State and National programmes. Despite previous studies in basketball linking anthropometric and fitness test scores with standard of play (McKenzie, 1985), player success (Angyan, Teczely, Zalay, \& Karsai, 2003; Hoare, 2000), playing time (Hoffman, Tenenbaum, Maresh, \& Kraemer, 1996), position (Latin, Berg, \& Baechle, 1994), and team success (Groves \& Gayle, 1993), the information available for coaches is limited to basic descriptive statistics collected on small samples of basketball players (Ackland, Schreiner, \& Kerr, 1997; Bale, 1991; Hoffman, Fry, Howard, Maresh, \& Kraemer, 1991). While some studies have gone beyond one year (Hunter, Hilyer, \& Forster, 1993; Lamonte, McKinney, Quinn, Bainbridge, \& Eisenman, 1999) and used more than 100 athletes (Berg \& Latin, 1995; Kellis, Tsitskaris, Nikopoulou, \& Mousikou, 1999; Latin et al., 1994), they are limited in their practical application and statistical power. Interpreting results from studies using large numbers of players in different locations is often difficult due to differences in test protocols (Latin et al., 1994). One recent study (Drinkwater, Hopkins, McKenna, Hunt, \& Pyne, 2005) examined changes in the fitness of Australian basketball players over time 
during a training programme, but did not address trends in the fitness of newly recruited players each year. Development of detailed reference values for test scores for players of different age groups, genders, and competitive standards are required to allow coaches to set appropriate fitness goals for specific groups of junior basketball players.

Although fitness improves through the adolescent years (Rowland, 1996), there is a trend in recent decades towards declining fitness in Australian school children (Tomkinson, Olds, \& Gulbin, 2003). This latter trend is generating concern both in the public health and sporting communities. There has been no exploration of how trends in the general population compare with the fitness of adolescents recruited into high-standard sporting programmes, although anecdotal reports from coaches suggest a trend of declining fitness in junior Australian basketball. Of particular interest are the secular trends of anthropometric and fitness test scores in the recruitment of new players to State and National programmes. Examination of secular trends would provide valuable information for coaches and administrators to help them clarify whether fitness trends in the general population are affecting the fitness of basketball players entering elite programmes, assess the value of prior recruitment patterns, identify important anthropometric and fitness factors in recruitment for elite programmes, and enhance the physical preparation of junior players.

Team sports typically encompass a wide variety of anthropometric and fitness characteristics that allow individuals to play different positions in the team, and basketball is no exception (Trninic \& Dizdar, 2000). While some variation between athletes is understandable, establishing reference ranges for between-athlete variation both in anthropometric and fitness test results would allow coaches to identify exceptional results for talent identification purposes and assign remedial fitness training and goal setting. The aims of the present study were to determine the effects of age, gender, and competitive standard on anthropometric and fitness test scores in junior basketball players, and identify secular differences in newly recruited players over an 8-year period.

\section{Methods}

\section{Participants}

The sample comprised 1011 females (904 State players, 107 National players) and 1087 males (958 State players, 129 National players) entering Basketball Australia (BA) State and National training programmes. Athlete test scores were obtained during regularly scheduled fitness testing between 1996 and 2003. Individual athletes were tested $2.6 \pm 2.0($ mean $\pm s ;$ minimum $=1$, maximum $=14)$ occasions over $0.8 \pm 1.0$ year. The ages of the four groups were as follows: National males $17.1 \pm 1.0$ years (range 15-19), National females $16.7 \pm 1.2$ years (range 14-19), State males $15.7 \pm 0.9$ years (range 13-20), and State females $15.5 \pm 0.9$ years (range 13-21). The participants (or parent/legal guardian) provided written informed consent for testing, training, data collection, and publication of results as part of their Scholarship Agreement with the Australian Institute of Sport (AIS) and/or BA Intensive Training Centre (ITC) programmes.

\section{Experimental design}

Junior sport typically functions in a tiered system where the better players at a particular level graduate to the next higher level, moving from local competitions to State and eventually National teams. All National players participated at National under-16 and under-18 men's and women's Australian Junior Camps and/or were on full-time scholarships with the AIS men's and women's basketball teams. State players trained at one of seven State or Territory ITC programmes around Australia. Tests were conducted in accordance with test protocols prescribed by the national sporting body (Stapff, 2000). Group sizes for testing ranged from 5 to 70 athletes but were typically $10-14$ players, approximating the number of players on a basketball team. All results were compiled from the records of routine fitness testing conducted on players at each state ITC, at the Australian Junior Camps, and the AIS.

\section{Description of tests}

Anthropometry. Athletes' stretched height and body mass were measured using a stadiometer and digital scales respectively. The typical error of measurement (Hopkins, 2000) for measuring both height and body mass, including biological variation, is typically not more than $1 \%$ (Norton et al., 1996). The sum of seven skinfold thicknesses from the triceps, subscapular, biceps, supraspinale, abdominal, front thigh, and medial calf was measured with a typical error of measurement $<3 \%$ for inter-tester variability (Norton et al., 1996).

Fitness tests. Two maximal effort tests were used to indicate leg power: $20-\mathrm{m}$ sprint and vertical jump (Stapff, 2000). The fastest of three attempts of elapsed movement time from a stationary standing start to a point $20 \mathrm{~m}$ away was recorded using electronic light gates (SWIFT Performance Equipment, Lismore, NSW, Australia). A vertical jump 
test measured the best of three maximal countermovement jump heights allowing a single backward step using a YardStick vertical jump apparatus (SWIFT Performance Equipment, Lismore, NSW, Australia). Aerobic fitness was determined by repeatedly running back and forth along a $20-\mathrm{m}$ straight line at a progressively faster pace set by a recorded tone until the athlete could no longer run in rhythm with the tone, a test that has been previously demonstrated to have a high correlation with maximal oxygen consumption (Ramsbottom, Brewer, \& Williams, 1988). All athletes had performed these tests many times previously at State and National standard so we assumed a minimal learning effect for our results.

\section{Fitness test reliability}

To isolate biological and technical error in the measurement from physiological adaptations to training, the typical error of measurement was established with a series of test-retest reliability trials (Hopkins, 2000). A subgroup of 12 male and 12 female National players completed duplicate tests within 5-7 days under standardized conditions before analysis of the annual fitness testing data.

\section{Statistical analyses}

Log transformation and repeated-measures mixed linear modelling using Proc Mixed in the Statistical Analysis System software (Version 8.1, SAS Institute, Cary, NC, USA) provided estimates of percent differences in means (fixed effects) and between- and within-athlete coefficients of variation (CV) (random effects) for each fitness and anthropometric test. Separate analyses were performed for each sex at each standard (i.e. State female, National female, State male, and National male).

The fixed effects in each analysis were year, year $\times$ year, age, and age $\times$ age, where year was a numeric between-participant effect representing the calendar year when each player was recruited (1996-2003), and age was a numeric betweenparticipant effect representing the age of the player at recruitment (14-19 years). Quadratic effects for age and year were included in the model as the simplest approach to allow for non-linear effects of these predictors.

The random effects in the analyses were athlete and the residual, where athlete was the identity of the athlete (to estimate pure between-athlete variance). Means for different ages of recruitment were adjusted to the year 1998. Means for calendar years of recruitment were estimated without adjustment for age by using a simpler fixed-effects model, in which age was omitted.
We compared mean estimates for a given anthropometric or fitness test at different ages of recruitment by calculating the Cohen, or standardized, effect size (ES), defined as (difference in means)/ standard deviation (Cohen, 1988). To interpret the magnitude of differences, we modified Cohen's guidelines for qualitative interpretation of effect size (Cohen, 1988) to 0.2, 0.6, and 1.2 as thresholds for small, moderate, and large effects. For the sake of parsimony, we report only effects that were at least moderate in size $(\mathrm{ES}>0.6)$. We also calculated the likelihood that the true value of estimated differences in fitness and anthropometric tests were larger than the smallest worthwhile (practical) difference and assigned thresholds for assigning qualitative terms to chances, described in Table I (Liow \& Hopkins, 2003). Differences in means between groups were expressed using $95 \%$ confidence intervals $(95 \% \mathrm{CI})$.

To compare the magnitude of variation in a given anthropometric or fitness test score between player standards for each sex, we divided the National standard deviation by that for the State. Ratios within a range of $0.9-1.1$ were considered trivial (see justification at http://yahoogroups.com/groups/ sportscience/message/2538); ratios $>1.1$ indicate test scores for National athletes were substantially more variable than for State athletes, whereas ratios $<0.9$ indicate test results for National athletes were substantially less variable than for State athletes.

\section{Results}

\section{Fitness test reliability}

Reliability testing was conducted only on National athletes. The shuttle run had the highest typical error of measurement (TEM) of $4.1 \%$ (0.4 levels), while the $20-\mathrm{m}$ sprint test TEM was $1.3 \%(0.04 \mathrm{~s})$ and the vertical jump TEM was $1.4 \%(0.5 \mathrm{~cm})$.

\section{Playing standard (State vs. National)}

National male and female players were better than their State counterparts on all anthropometric and fitness tests, with effect sizes ranging from 0.02 (trivial) to 0.80 (moderate). Differences between playing standards were generally small except male height $(7 \mathrm{~cm}, 95 \% \mathrm{CI} \pm 3.4 \mathrm{~cm}$, ES moderate) and male body mass $(6.7 \mathrm{~kg}, 95 \% \mathrm{CI} \pm 4.0 \mathrm{~kg}$, ES moderate). Standardized differences in means between playing standards are summarized in Table I.

Variation within the National and State groups on any given test, as estimated by the betweenparticipant coefficient of variation (CV), tended to be similar, with the National groups being slightly less variable. Ratios comparing National and State CV (i.e. National/State) reveal that the variation was 
Table I. Effect sizes and qualitative descriptors of differences between standards of players (State vs. National).

\begin{tabular}{|c|c|c|c|c|c|c|c|c|}
\hline \multirow[b]{2}{*}{ Test } & \multirow[b]{2}{*}{ Gender } & \multicolumn{4}{|c|}{ Mean score $\pm s$} & \multicolumn{3}{|c|}{ Magnitude of National-State effects } \\
\hline & & State & $\begin{array}{c}\text { State } \\
N\end{array}$ & National & $\begin{array}{c}\text { National } \\
\quad N\end{array}$ & $\begin{array}{c}\text { Effect } \\
\text { size } \pm 95 \% \mathrm{CI}\end{array}$ & $\begin{array}{l}\text { Qualitative } \\
\text { descriptor }^{\text {a }}\end{array}$ & $\begin{array}{l}\text { Chances of } \\
\text { National better } \\
\text { than State }\end{array}$ \\
\hline \multirow[t]{2}{*}{ Vertical jump (cm) } & $\mathrm{F}$ & $45.6 \pm 6.5$ & 2262 & $45.7 \pm 6.1$ & 232 & $0.02 \pm 0.37$ & Trivial & 17\%: unlikely \\
\hline & M & $59.1 \pm 7.3$ & 2327 & $62.0 \pm 8.4$ & 245 & $0.36 \pm 0.40$ & Small & $78 \%$ : likely \\
\hline \multirow[t]{2}{*}{ Shuttle (levels) } & $\mathrm{F}$ & $9.3 \pm 1.6$ & 2163 & $10.0 \pm 1.4$ & 221 & $0.47 \pm 0.41$ & Small & $90 \%$ : likely \\
\hline & M & $11.2 \pm 1.6$ & 2242 & $11.6 \pm 1.4$ & 246 & $0.29 \pm 0.40$ & Small & $67 \%$ : possibly \\
\hline \multirow[t]{2}{*}{ Skinfolds (mm) } & $\mathrm{F}$ & $103.4 \pm 28.3$ & 1377 & $95.9 \pm 24.3$ & 273 & $-0.28 \pm 0.36$ & Small & $67 \%$ : possibly \\
\hline & M & $68.4 \pm 22.3$ & 1389 & $67.5 \pm 20.6$ & 268 & $-0.04 \pm 0.36$ & Trivial & 19\%: unlikely \\
\hline \multirow[t]{2}{*}{ Sprint (s) } & $\mathrm{F}$ & $3.42 \pm 0.16$ & 2217 & $3.38 \pm 0.16$ & 221 & $-0.25 \pm 0.46$ & Small & 59\%: possibly \\
\hline & $M$ & $3.15 \pm 0.16$ & 2256 & $3.08 \pm 0.13$ & 244 & $-0.47 \pm 0.45$ & Small & $88 \%$ : likely \\
\hline \multirow[t]{2}{*}{ Body mass (kg) } & $\mathrm{F}$ & $65.6 \pm 8.6$ & 2370 & $69.6 \pm 8.5$ & 277 & $0.47 \pm 0.37$ & Small & $93 \%$ : likely \\
\hline & M & $77.3 \pm 11.0$ & 2369 & $84.0 \pm 10.3$ & 268 & $0.63 \pm 0.38$ & Moderate & 99\%: very likely \\
\hline \multirow[t]{2}{*}{ Height (m) } & $\mathrm{F}$ & $174 \pm 7$ & 2396 & $178 \pm 8$ & 268 & $0.47 \pm 0.38$ & Small & $92 \%$ : likely \\
\hline & $M$ & $188 \pm 9$ & 2340 & $195 \pm 9$ & 248 & $0.80 \pm 0.40$ & Moderate & $100 \%$ : definitively \\
\hline
\end{tabular}

Note: State $\mathrm{N}$ and National $\mathrm{N}$ represent the total number of tests performed by all subjects. Positive values of the effect size indicates National scores were higher than State scores. In skinfold and sprint tests, lower scores are better. Probability reflects the likelihood that National players were at least a small effect size better $(>0.2 \times s)$ than State players. $95 \% \mathrm{CI}=95 \%$ confidence interval of the true effect size.

${ }^{\mathrm{a}}$ Criteria for magnitude: $<0.2$, trivial; $0.2-0.6$, small; $0.6-1.2$, moderate; $>1.2$, large.

${ }^{\mathrm{b}}$ Thresholds for assigning qualitative terms to chances of substantial effects were as follows: $<1 \%$, almost certainly not; $<5 \%$, very unlikely; $<25 \%$, unlikely; $<50 \%$, possibly not; $>50 \%$, possibly; $>75 \%$, likely; $>95 \%$, very likely; $>99 \%$ almost certain.

higher in National players for male vertical jump (1.14) and female height (1.18) only. Ratios of less than 1.00, indicating State variation exceeded National variation, were evident for the male shuttle run (0.84), female skinfolds (0.86), and male sprint (0.83). Variation between female groups was similar for the 20-m sprint (0.99) and body mass (1.00). While State variation exceeded National variation on all other tests, differences were generally trivial $(0.92-0.95)$. Estimations of all between-group ratios showed a similar degree of uncertainty $(\times / \div 1.10)$. We have chosen to express the typical variation using a $\times / \div$ factor (e.g. $\times / \div 1.10$ ) rather than a $\pm \%$ factor (e.g. $\pm 10 \%$ ) because in log-normally distributed variables, typical variation is better described with a $\times 1 \div$ factor when the variation is more than a few percent. For example, 100 units $\times / \div 2.00$ is not $\pm 100 \%$, but $+100 \%$ (i.e. 200 units) or $-50 \%$ (i.e. 50 units).

\section{Gender}

At both National and State standards, males exhibited higher mean scores than females on all anthropometric and fitness tests, with effect sizes ranging from 1.1 to 2.1 . Substantially more variation existed among females than males only for skinfolds (by a factor of 1.23), while males exhibited more variation in vertical jump (1.25), mass (1.25), and height (1.13). Variation between the sexes was similar for sprint time (1.06) and identical for the shuttle run (1.00). The uncertainty of estimates of all ratios of variation between males and females was $\times / \div 1.10$.

\section{Age differences at recruitment (14-19 years)}

Anthropometry. All data are expressed graphically in Figure 1A-C. While there was a trend for older players to have more favourable anthropometric test scores when recruited into their first year of State and National programmes, the higher test scores of older athletes occasionally plateaued or reversed at approximately 17 years. National groups showed the greatest difference in height between older and younger players, with older athletes being taller between 14 and 17 years (standardized effect sizes, $\pm 95 \%$ CI of ES: females: 0.93, \pm 0.93 ; males: 0.66, \pm 1.20 ). For the older juniors, the stature of females entering National programmes declined between 17 and 19 years $(0.55, \pm 0.93)$. The height difference for State players continued to increase up to 18 years (males: $1.15, \pm 0.54$; females: $0.54, \pm 1.57$ ) (Figure 1A). While there is a substantial amount of uncertainty in some estimates, estimating growth differences in this age group is understandably imprecise.

Body mass between 14 and 17 years was greater in newly recruited older females with older players being heavier (National: 1.89, \pm 0.80 ; State: 0.73, $\pm 0.44)$. However, between 17 and 19 years the older National players were lighter $(1.05, \pm 0.87)$. Older male athletes had more body mass in their recruitment year at both National and State level between 14 and 19 years (National: 0.76, \pm 1.39 ; State: 2.13, \pm 1.54 ) than younger players (Figure 1B).

Skinfolds were greater in older National females between 14 and 17 years $(1.15, \pm 1.54)$ but were 

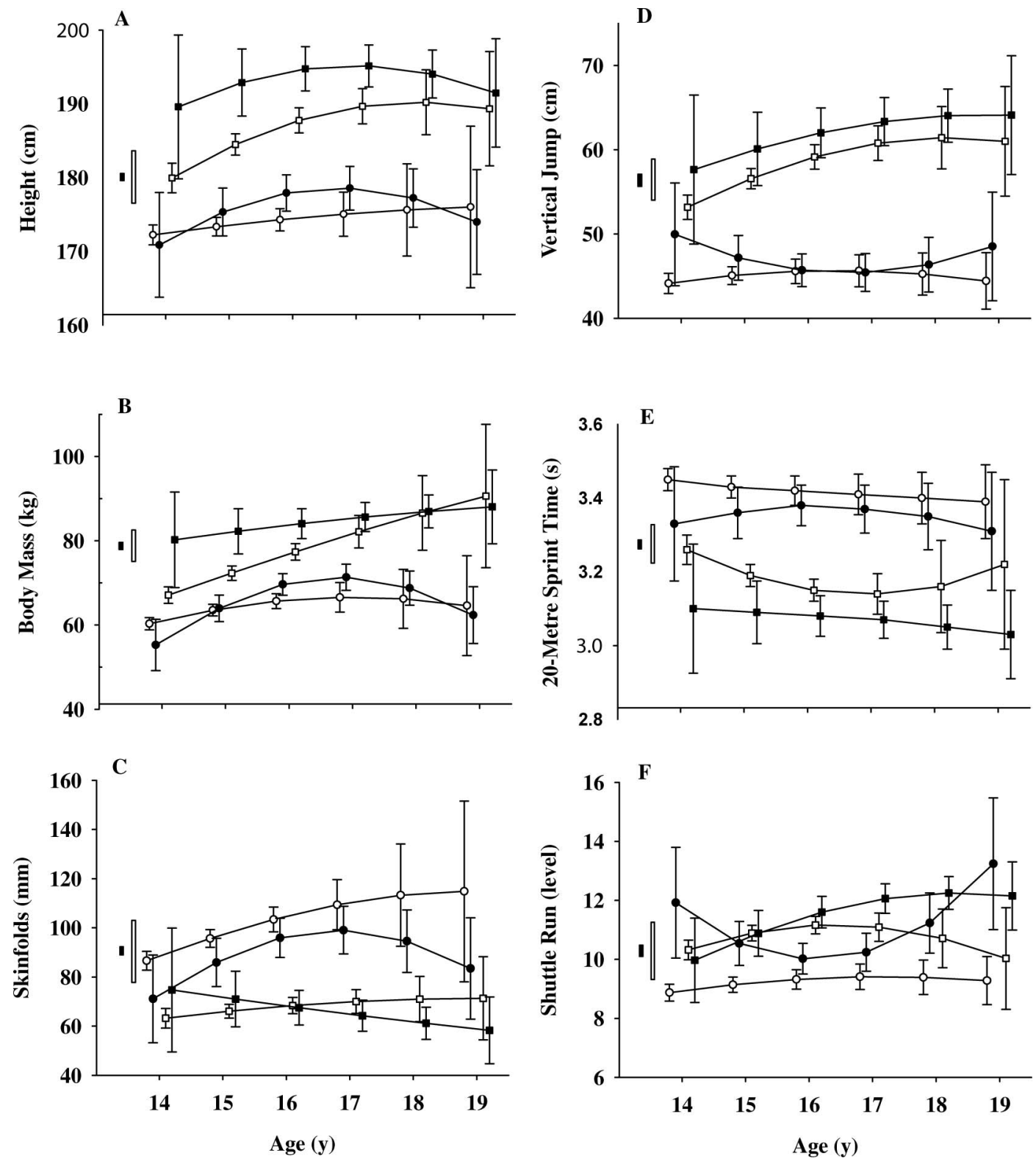

Figure 1. Group estimates for National females $(\bullet)$, National males

, State females (O), and State males ( $\square$ ) showing the scores of different groups throughout the age range, adjusted to recruitment year 1998. Error bars represent $95 \%$ confidence limits while the filled bars (I) represent the typical error of measure for the test and the open bars $(\mathbb{D})$ represent the between-athlete standard deviation averaged over all groups. Group means have been slightly offset from age for clarity.

lower in older athletes between 17 and 19 years (0.64, \pm 0.94$)$. While older National males had lower skinfolds between 14 and 19 years (0.80, \pm 1.39$)$, older State females had higher skinfolds $(1.00, \pm 1.31)$ over the same age range (Figure 1C).

Fitness. There were also variable patterns in fitness tests between the different ages of recruitment. In general, we observed better fitness in older players (Figure 1D-F). For National females, players recruited at 14 years jumped $4.5 \mathrm{~cm}$ higher $(0.75$, $\pm 1.07)$ than those recruited at 17 years, but males recruited at 19 years jumped higher than those recruited at 14 years (National: $0.76, \pm 1.12$; State: 1.13, \pm 0.54 ; Figure 2) (Figure 1D).

State male players up to 17 years had faster sprint times when recruited than 14-year-olds (0.74, \pm 0.42 ) (Figure 1E). National females recruited at 14 years scored 1.7 levels higher on the shuttle run than those recruited at 17 years $(1.17, \pm 1.38)$, although this difference was narrowed considerably between those recruited at ages 17 and 19 years $(2.09, \pm 1.68)$. State males recruited at 16 years had higher scores than those recruited at 19 years $(0.69$, $\pm 1.07)$, while National males recruited at 18 years 


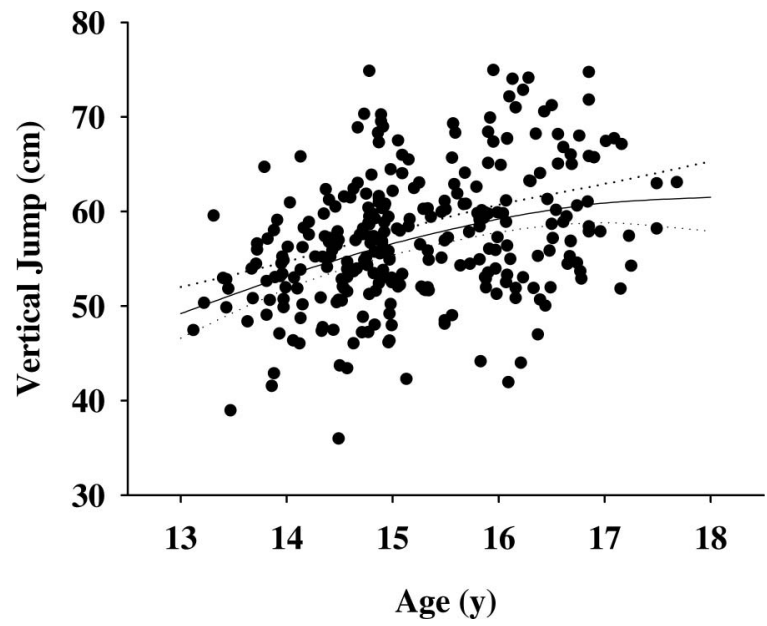

Figure 2. Scatter plot to illustrate additional detail to the origins of the State male plot of Figure 1D, indicating the age trend of State male vertical jump $(n=1164)$. This figure represents a typical plot for the age effect of any test, showing the distribution of individual players and the mean trend line from 13 to 19 years of age. In this example, older State male players are jumping higher than younger players. The graph plots individual player test scores $(\bullet)$ while the solid trend line refers to the modelled estimate over time, and the dotted lines refer to the upper and lower $95 \%$ confidence limits for the true mean.

had higher shuttle run scores than those recruited at 14 years $(1.67, \pm 1.96)$ (Figure $1 \mathrm{C}$ ).

\section{Secular Differences (1996-2003)}

Anthropometry. All anthropometric data are shown in Figures $3 \mathrm{~A}-\mathrm{C}$. There was little change in anthropometry scores in players recruited between 1996 and 2003, and any differences that existed tended to be small. Between 1999 and 2003, successive groups of National females had lower skinfolds (standardized effect sizes, $\pm 95 \%$ confidence interval of ES: $0.89, \pm 0.63)$ and height $(0.58, \pm 0.69)$, with newly recruited National males also showing lower skinfolds $(0.65, \pm 0.65)$ in 2003 (Figure 3C).

Fitness. There was a general decline in the quality of fitness test scores between newly recruited players during the study period, although scores did not decline uniformly for all groups on all tests. Between 1996 and 2000, successive cohorts of National females increased jump height (ES: 0.64, \pm 0.75 ) while State females experienced a decline in jump height $(0.83, \pm 0.38)$ (Figure 3D). Both National groups experienced a reduction in the quality of sprinting, with increases in $20-\mathrm{m}$ sprint time (females: $0.70, \pm 1.04$; males: $0.82, \pm 0.69$ ). The slowing in sprint times over the study period in State athletes was at least twice that of National athletes (National females: $0.70 \pm 1.04$; National males: $0.82 \pm 0.69$; State females: $1.45 \pm 0.50$; State males:
$2.47 \pm 0.55$ ) (Figure 3E). The magnitude of the increase in sprint time performance was similar to the decline in aerobic fitness over the same period. Shuttle run scores were lower in both National groups (females: $1.11, \pm 1.03$; males: $0.68, \pm 0.74$ ) in 2003 than in 1996 (Figure 3F).

Age. The age of players at recruitment fell both for the male and female National teams over the study period, with females declining in age from $17.5 \pm 0.9$ to $16.3 \pm 1.3$ years $(-1.2$ years, $95 \% \mathrm{CI}$ \pm 0.8 ) and males declining in age from $18.1 \pm 0.2$ to $16.2 \pm 1.0$ years $(-1.9$ years, $95 \% \mathrm{CI} \pm 0.8)$. The State groups also declined in age but to a lesser extent: females' age declined from $15.4 \pm 1.1$ to $14.8 \pm 0.9$ years $(-0.6$ years, $95 \% \mathrm{CI} \pm 0.4)$ and that of males from $15.6 \pm 1.0$ to $14.9 \pm 1.0$ years $(-0.7$ years, $95 \% \mathrm{CI} \pm 0.4)$.

\section{Discussion}

This is the first study to assess comprehensively the effects of recruitment age and recruitment year on fitness and anthropometric testing in junior basketball players. We examined the results of a standardized battery of tests on male and female players $(n>1000)$ at different standards of competition over an 8-year period. We systematically compared group means in anthropometric and fitness test results between junior male and female basketball players, State and National players, players of different chronological ages, and players recruited in different calendar years. We found that estimated means varied at different ages for different groups, with test scores tending to be better for younger juniors at recruitment age $14-17$ years than older juniors aged 17-19 years. While anthropometric measures were largely unchanged in recent calendar years, the speed and endurance of players have generally declined by small amounts. The National males and females had better scores with lower variation than State players indicating that the test protocols have potential use for talent identification purposes.

\section{Age differences at recruitment}

Older athletes generally scored better in anthropometric and fitness tests with greater improvements observed in National players. The lower skinfolds and higher body mass with older recruitment age for National males probably reflects greater development of muscle mass. This contention is supported by the higher performance-to-body mass ratio evident in improvements in vertical jump and sprint time. In State males, the unfavourable differences in shuttle run and sprints in older players after 17 years 

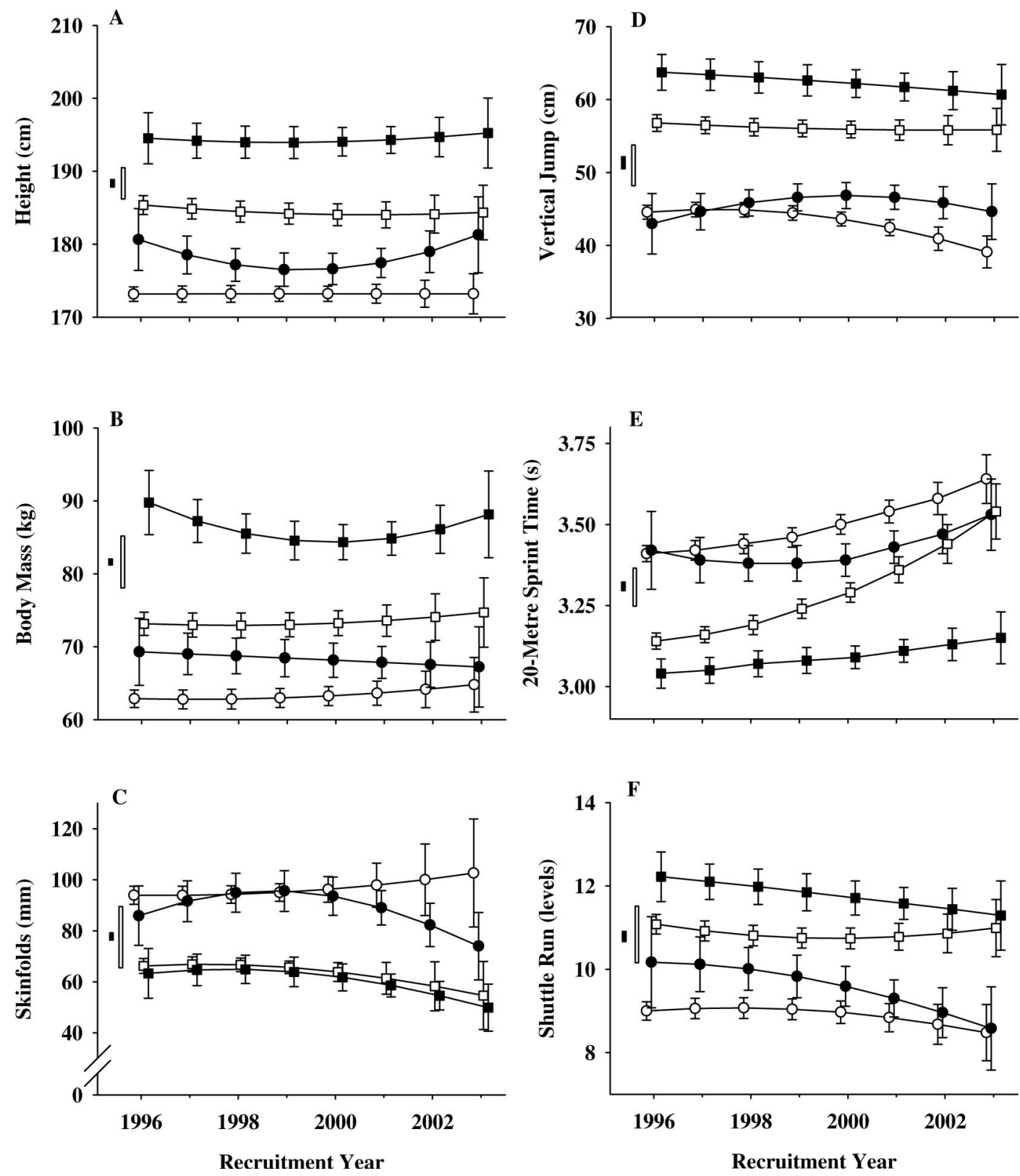

Figure 3. Group estimates showing actual trends for National females $(\bullet)$, National males $(\boldsymbol{\square})$, State females $(O)$, and State males $(\square)$ comparing year of recruitment between groups. Error bars represent $95 \%$ confidence limits while the filled bars (I) represent the typical error of measure for the test and the open bars $(\mathbb{D}$ represent the between-athlete standard deviation averaged over all groups. Group means have been slightly offset from year for clarity.

are indicative of a poorer performance-to-weight ratio associated with increasing skinfolds. The opposite trend can be seen in the female groups, with National females decreasing skinfolds and improving fitness test scores, particularly beyond 17 years. The more favourable National players' anthropometric and court measures with age implies that these players are fitter, probably as a consequence of more extensive and intensive physical conditioning associated with this standard of programme, especially beyond 17 years. State players participate in part-time training programmes and generally do not undertake the comprehensive physical conditioning programmes of their full-time National counterparts. Consequently, State players exhibit typical adolescent gains in height and body mass but not the same magnitudes of improvements in skinfolds and measures of fitness as National players. The difference in vertical jump between younger and older State basketball players was somewhat less than that in basketball players of similar ages (13-19 years) in other research (ES males: 1.13 vs. 2.10; ES females: 0.05 vs. 0.52 ) (Kellis et al., 1999). 
The decline in height of National players between the recruitment ages of 18 and 19 years does not indicate that individuals in this group become shorter with age, but that newly recruited players tend to be shorter than newly recruited 16- and 17-year-old players. National players in the 14-17 year age category might be recruited based on height, while older players are selected based on skill. Most of the taller players appear to have been recruited by 17 years of age.

\section{Secular differences}

The test results in the current study represent the outcome of recruiting practices in State and National programmes. Variable trends in anthropometry and fitness test results over the eight calendar-year period were observed: some test results showed an improvement, some were comparatively unchanged, and others showed a small decline. Clearly, there has been a conscious decision of National female coaches to recruit taller players. There was a trend for declining body mass in both National males and females, though the effects were small, and skinfolds showed moderate decreases in three of the four groups studied. Comparing 2003 with 1996, most group characteristics remained stable or showed decrements in vertical jump, 20-m sprint, and shuttle run performance. These findings confirm anecdotal reports that some aspects of fitness in newly recruited junior players have declined in recent years. Clearly, the basketball authorities need to address these important issues of player recruitment and fitness in junior programmes.

We also observed a trend towards recruitment of younger players both in National and State programmes in recent years. This trend is a concern because younger players tend to be less fit, particularly below 17 years. We believe that the secular decline in fitness can be partially attributed to the decline in age of recently recruited players. Potential strategies for improving fitness in the future include greater fitness development of younger players at lower standards (e.g. school and local club leagues), and the recruitment of players close to the upper limit of their age group, though care should be taken not to overlook the early development of young tall players solely in the interest of gaining fitness. The implications of declining body size and fitness on the success of Basketball Australia is unclear. While assessing win-loss records of Basketball Australia teams over the assessed time period is tempting, many variables that determine the win-loss record are largely dependent on opposing teams. The purpose of this research was to investigate one component of many that contribute to team success. As previously discussed, body composition and fitness have been identified as contributing to many facets of basketball success (Angyan et al., 2003; Groves \& Gayle, 1993; Hoare, 2000; Hoffman et al., 1996; Latin et al., 1994; McKenzie, 1985) and thus declining fitness should be a concern to Basketball Australia coaches.

One possible explanation for declining fitness is that it reflects a decline in the population of Australians in this age group. Research investigating fitness of Australian school-aged children (Tomkinson et al., 2003) has demonstrated that over a similar period (1995-2000), aerobic fitness was declining by $0.4-0.8 \%$ per year. Our results show that the decline in aerobic fitness is approximately $1 \%$ per year when averaged across groups, ranging from a decrease of $0.8 \%$ in State males between 1996 and 2003 to greater than $15 \%$ in National females. Another possible explanation for the decline in fitness is that the participation rate of basketball in boys aged $5-14$ years declined by $24 \%$ between 1997 and 2003 , though it increased slightly in girls (7.6\%). Other sports such as swimming have increased participation dramatically in boys (38\%) and girls $(27 \%)$ since 1997 (McLennan, 1999; Trewin, 2005). With the overall participation rate of children in organized sport in Australia decreasing only slightly from $62 \%$ to $61 \%$ between 1997 and 2003 (McLennan, 1999; Trewin, 2005), Australian basketball may be experiencing a drain of fitter players to other sports. Arguably, strategies to improve player fitness could include simply training players more or having a greater focus during practices on fitness, but the likely ramifications of such a strategy would be player burnout and declining player skill.

\section{Standard of programme and gender differences}

The National players generally scored better on anthropometric and fitness tests than State players. The higher test scores likely reflect the National players' greater commitment and intensity in training and possibly higher genetic capacities for these tests. These differences could be a result of greater muscle mass in National players, as reflected in greater body mass yet lower skinfolds. Fitter players might also be able to perform better during team selection camps. Our results are in accordance with studies such as those of Hoare (2000), who concluded that performance on anthropometric and fitness tests accounted for $\sim 40 \%$ in variance of playing performance, and Hoffman et al. (1996), who reported that fitness test scores accounted for up to $20 \%$ of playing time when the athlete was well known to the coach or up to $80 \%$ if the athlete was not known. Collectively, this evidence underscores the importance of welldeveloped fitness attributes for junior basketball players. 
The differing anthropometric characteristics between groups could simply reflect variations in biological maturity and/or the recruitment strategies of coaches, with the greater fitness of National players reflecting greater biological maturity, the recruitment strategies of coaches, and/or factors relating to training history and experience. While there were no direct measures of biological age in this study, the height of National players plateaued one year earlier than that of the State players, possibly indicating that the National players had reached biological maturity one year earlier then the State players. Inspection of the fitness test results at 19 years, presumably when both groups had reached biological maturity based on stability of height, reveals National players were superior. It would appear that regardless of biological maturity, National players remain bigger and fitter than State players.

The differences between males and females are consistent with previous research showing that adolescent males are typically taller and heavier (Malina, Bouchard, \& Bar-Or, 1991), have between $5-20 \%$ more aerobic capacity (Beunen \& Malina, 1996), and score at least one standard deviation greater on most tests of fitness (Beunen \& Malina, 1996) than adolescent girls. Especially large differences between males and females were evident in vertical jump, skinfolds, and body mass, reflecting a higher ratio of performance to body mass for males in this age group (Rowland, 1996). These gender differences are explained by the natural difference in biological maturation, with males having a longer pubertal growth period and faster peak height and body mass growth (Rowland, 1996). Coaches of junior athletes should therefore anticipate increasingly large differences in anthropometric and court test scores between boys and girls as adolescence progresses.

\section{Implications of test variability}

Quantifying the variability of different tests allows coaches and sport scientists to evaluate the usefulness of a test. A test requires a typical error of measurement of less than 0.20 of the test's betweenathlete standard deviation to provide confident assessment of small (worthwhile) differences between athletes (Hopkins, 2000). While the typical errors of measurement of height and body mass are reasonably well established (Norton et al., 1996) and that of skinfolds is specific to each individual tester, the typical error of measurement of fitness tests needed to be established and included when interpreting results. On the basis of our results comparing the typical errors of measurement and betweenathlete variability, all of the tests examined in this study can be used to identify meaningful differences in fitness and anthropometric characteristics between athletes. Furthermore, the National groups had higher mean scores on all tests with lower variability on most tests, underlining the value of these tests as an athlete selection tool.

The low percent variation in height $(\sim 4.5 \%)$ was initially surprising, given the apparent range of height in the different positions in basketball. However, a variation of $4.5 \%$ is equivalent to $7.8 \mathrm{~cm}$ in the mean height of females and $8.5 \mathrm{~cm}$ in males, so this magnitude of variation is understandable. The considerable variations in body mass, skinfolds, and shuttle run likely represent differences between the demands of different positions in basketball. Anthropometric testing might be useful for assigning players to particular positions or assessing the effectiveness of dietary practices and strength and conditioning programmes. The small variation in sprint times indicates that this characteristic is homogeneous, although a $4.8 \%$ variation of $3.1 \mathrm{~s}$ represents $0.15 \mathrm{~s}$, which over $20 \mathrm{~m}$ equates to a displacement of $90 \mathrm{~cm}$, potentially a critical distance on a basketball court. Our estimate of the smallest worthwhile difference is $\sim 0.04 \mathrm{~s}$, equivalent to a distance of approximately $20 \mathrm{~cm}$.

The basketball community must also consider individual variation in size and fitness of players, even at the elite standard. The classic example often cited as the exception to the trend of basketball players being large is Spud Webb, who, despite being only $1.67 \mathrm{~m}$ tall and having a body mass only $60 \mathrm{~kg}$, played 12 seasons in the American National Basketball Association. Doubtless there are many other examples of extraordinary players who could easily have been overlooked if anthropometric and fitness test scores were the sole criteria for selection. Clearly, a range of sport-specific methods should be used to assess basketball players (Trninic, Perica, \& Dizdar, 1999), but our results are consistent with those of other studies supporting the value of anthropometric and fitness testing for team sports (Hoare, 2000; Hoare \& Warr, 2000; Pienaar, Spamer, \& Steyn, 1998).

\section{Conclusions}

This research had a large sample size to quantify the magnitude of a variety of effects on elite Australian junior basketball players' anthropometric and fitness test scores. We found an overall large effect of gender and a small, but still meaningful, effect of competitive standard. The more favourable scores with lower variability at higher standards indicate the value of fitness tests as a talent identification tool. The pattern of overall declining test scores and player age of Australian basketball players over an 8-year 
study period is a major issue for contemporary basketball. Coaches must consider the age of players they are selecting and the effect this will have on player fitness. The value of fitness and anthropometric testing is demonstrated by the National players having better scores with lower betweenathlete variability. Basketball organizations and individual teams should benefit from the administration of anthropometric and fitness testing of junior players.

\section{Acknowledgements}

The authors gratefully acknowledge the staff of Basketball Australia's National Office for their assistance with compiling fitness testing records. We also acknowledge the efforts of ITC and AIS coaches and athletes for their commitment to the testing programme.

\section{References}

Ackland, T. R., Schreiner, A. B., \& Kerr, D. A. (1997). Absolute size and proportionality characteristics of World Championship female basketball players. Fournal of Sports Sciences, 15, $485-490$.

Angyan, L., Teczely, T., Zalay, Z., \& Karsai, I. (2003). Relationship of anthropometrical, physiological and motor attributes to sport-specific skills. Acta Physiologica Hungarica, 90, 225-231.

Bale, P. (1991). Anthropometric, body composition and performance variables of young elite female basketball players. Fournal of Sports Medicine and Physical Fitness, 31, 173-177.

Berg, K., \& Latin, R. (1995). Comparison of physical and performance characteristics of NCAA division I basketball and football players. Fournal of Strength and Conditioning Research, 9, $22-26$.

Beunen, G., \& Malina, R. (1996). Growth and biological maturation: Relevance to athletic performance. In O. Bar-Or (Ed.), The child and adolescent athlete (pp. 3-24). Oxford: Blackwell Scientific.

Cohen, J. (1988). Statistical power analysis for the behavioral sciences (2nd edn.). Hillsdale, NJ: Lawrence Erlbaum Associates.

Drinkwater, E. J., Hopkins, W. G., McKenna, M. J., Hunt, P. H., \& Pyne, D. B. (2005). Characterizing changes in fitness of basketball players within and between seasons. International Fournal of Performance Analysis in Sport, 5, 107-125.

Groves, B., \& Gayle, R. (1993). Physiological changes in male basketball players in year-round strength training. Fournal of Strength and Conditioning Research, 7, 30-33.

Hoare, D. G. (2000). Predicting success in junior elite basketball players - the contribution of anthropometric and physiological attributes. Fournal of Science and Medicine in Sport, 3, 391-405.

Hoare, D. G., \& Warr, C. R. (2000). Talent identification and women's soccer: An Australian experience. Fournal of Sports Sciences, 18, 751-758.

Hoffman, J., Fry, A., Howard, R., Maresh, C., \& Kraemer, W. (1991). Strength, speed and endurance changes during the course of a division I basketball season. Fournal of Strength and Conditioning Research, 5, 144-149.
Hoffman, J., Tenenbaum, G., Maresh, C., \& Kraemer, W. (1996). Relationship between athletic performance tests and playing time in elite college basketball players. Fournal of Strength and Conditioning Research, 2, 67-71.

Hopkins, W. G. (2000). Measures of reliability in sports medicine and science. Sports Medicine, 30, 1- 15.

Hunter, G., Hilyer, J., \& Forster, M. (1993). Changes in fitness during 4 years of intercollegiate basketball. fournal of Strength and Conditioning Research, 7, 26-29.

Kellis, S., Tsitskaris, G., Nikopoulou, M., \& Mousikou, K. (1999). The evaluation of jumping ability of male and female basketball players according to their chronological age and major leagues. Fournal of Strength and Conditioning Research, 13, $40-46$.

Lamonte, M., McKinney, J., Quinn, S., Bainbridge, C., \& Eisenman, P. (1999). Comparison of physical and physiological variables for female college basketball players. Fournal of Strength and Conditioning Research, 13, 264-270.

Latin, R., Berg, K., \& Baechle, T. (1994). Physical and performance characteristics of NCAA division I male basketball players. Fournal of Strength and Conditioning Research, 8, $214-218$

Liow, D., \& Hopkins, W. (2003). Velocity specificity of weight training for kayak sprint performance. Medicine and Science in Sports and Exercise, 35, 1232-1237.

Malina, R., Bouchard, C., \& Bar-Or, O. (1991). Growth, maturation, and physical activity. Champaign, IL: Human Kinetics.

McKenzie, G. (1985). Basketball: Identification of anthropometric and physiological characteristics relative to participation in college basketball. National Strength and Conditioning Association fournal, 7, 34-36.

McLennan, W. (1999). Australian Social Trends, 1999. Canberra, ACT: Australian Bureau of Statistics.

Norton, K., Whittingham, N., Carter, L., Kerr, D., Gore, C., \& Marfell-Jones, M. (1996). Measurement techniques in anthropometry. In K. Norton \& T. Olds (Eds.), Anthropometrica (pp. 25-75). Sydney, NSW: University of New South Wales Press.

Pienaar, A. E., Spamer, M. J., \& Steyn, H. S., Jr. (1998). Identifying and developing rugby talent among 10-yearold boys: A practical model. Fournal of Sports Sciences, 16, 691-699.

Ramsbottom, R., Brewer, J., \& Williams, C. (1988). A progressive shuttle run test to estimate maximal oxygen uptake. British fournal of Sports Medicine, 22, 141-144.

Rowland, T. (1996). Developmental exercise physiology. Champaign, IL: Human Kinetics.

Stapff, A. (2000). Protocols for the physiological assessment of basketball players. In C. Gore (Ed.), Physiological tests for elite athletes (pp. 224-237). Champaign, IL: Human Kinetics.

Tomkinson, G. R., Olds, T. S., \& Gulbin, J. (2003). Secular trends in physical performance of Australian children: Evidence from the Talent Search program. Fournal of Sports Medicine and Physical Fitness, 43, 90-98.

Trewin, D. (2005). Yearbook Australia, 2005. Canberra, ACT: Australian Bureau of Statistics.

Trninic, S., \& Dizdar, D. (2000). System of the performance evaluation criteria weighted per positions in the basketball game. Collegium Antropologicum, 24, 217-234.

Trninic, S., Perica, A., \& Dizdar, D. (1999). Set of criteria for the actual quality evaluation of the elite basketball players. Collegium Antropologicum, 23, 707-721. 